\title{
A new Differential Optical Absorption Spectroscopy instrument to study atmospheric chemistry from a high-altitude unmanned aircraft
}

Jochen Stutz et al.

Correspondence to: Jochen Stutz (jochen@atmos.ucla.edu)

The copyright of individual parts of the supplement might differ from the CC-BY 3.0 licence. 

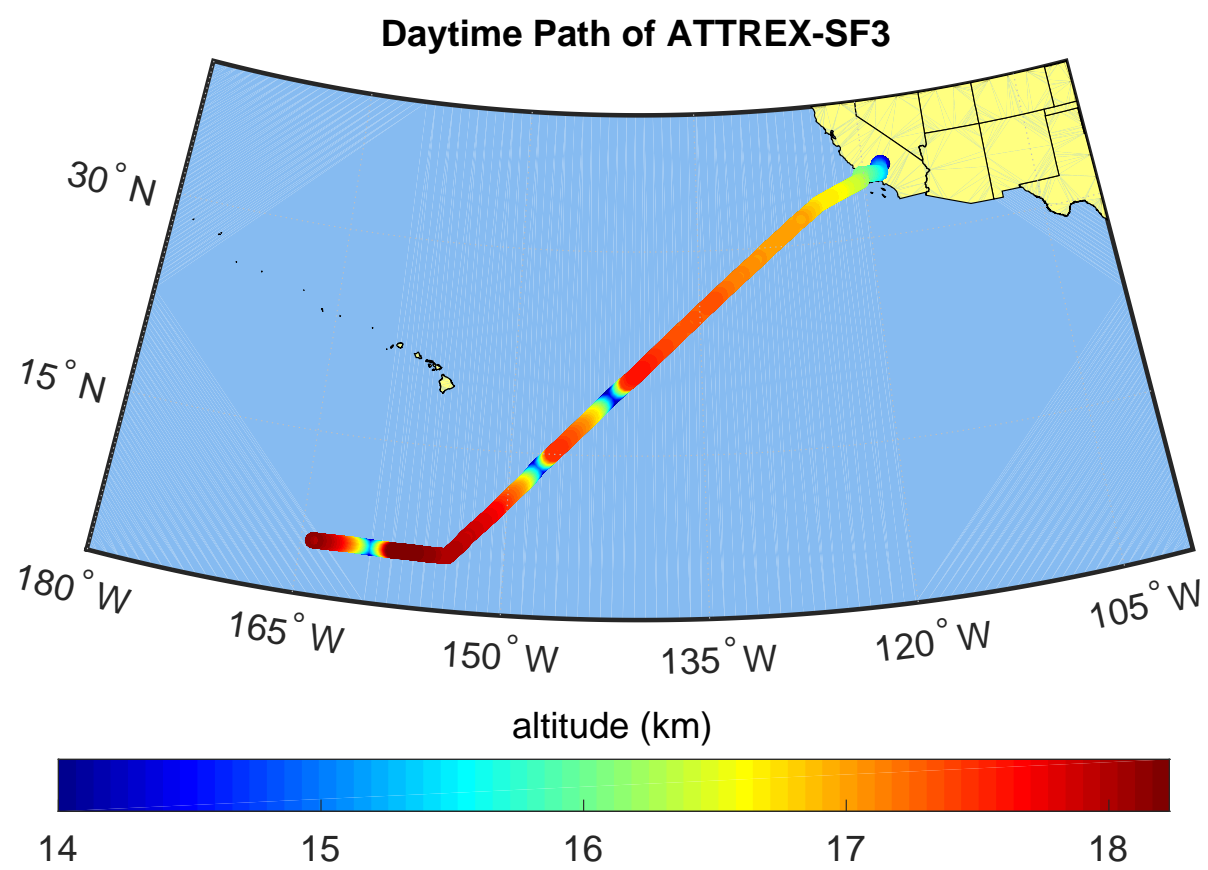

Figure S1. Daytime portion of ATTREX Science Flight 3 on Feb. 14, 2013. The aircraft altitude is color coded. Three vertical maneuvers can be clearly identified. 


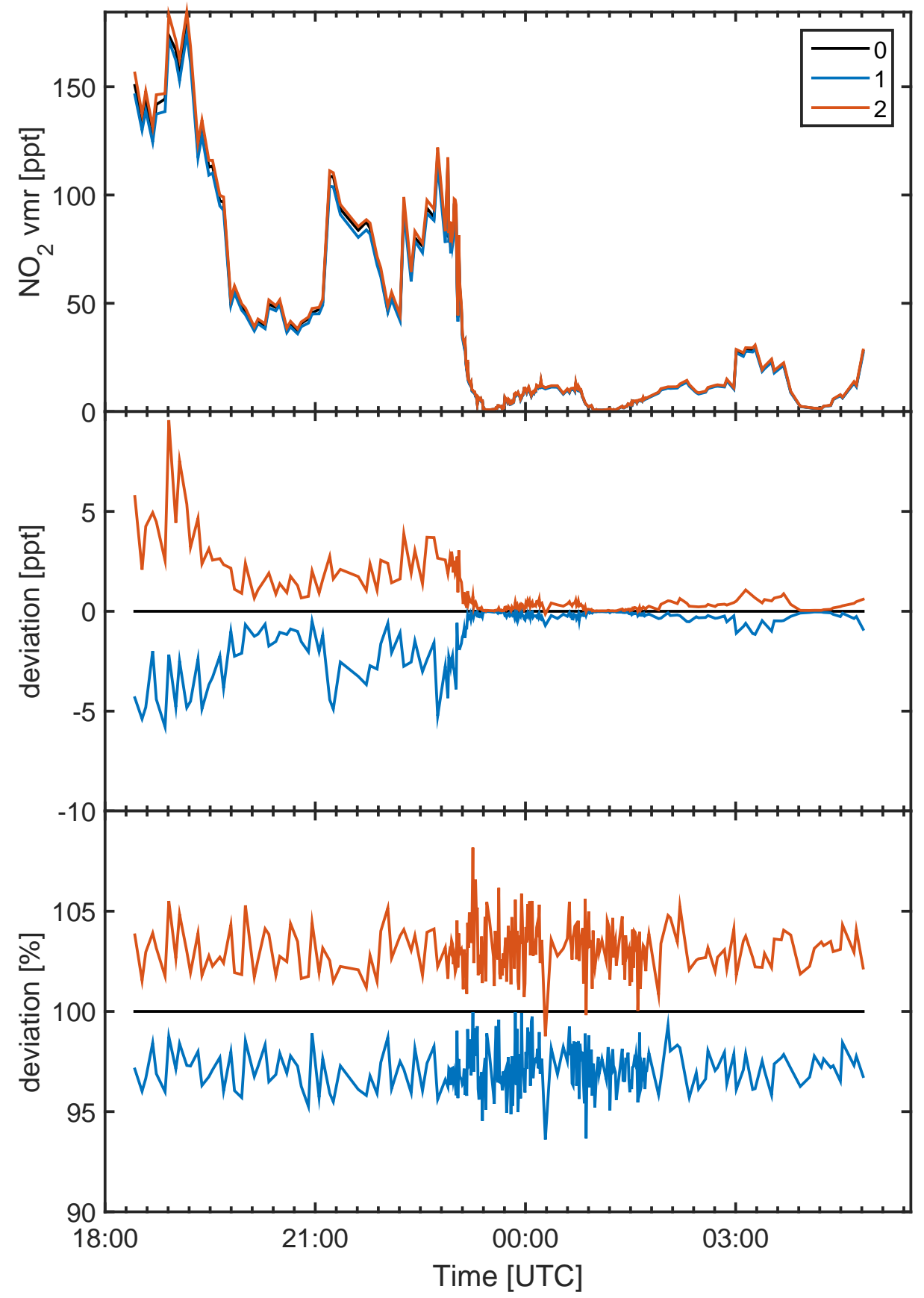

Figure S2. Sensitivity runs 0 (base run), 1, and 2 for $\mathrm{NO}_{2}$, according to the parameters given in Table 5 . 


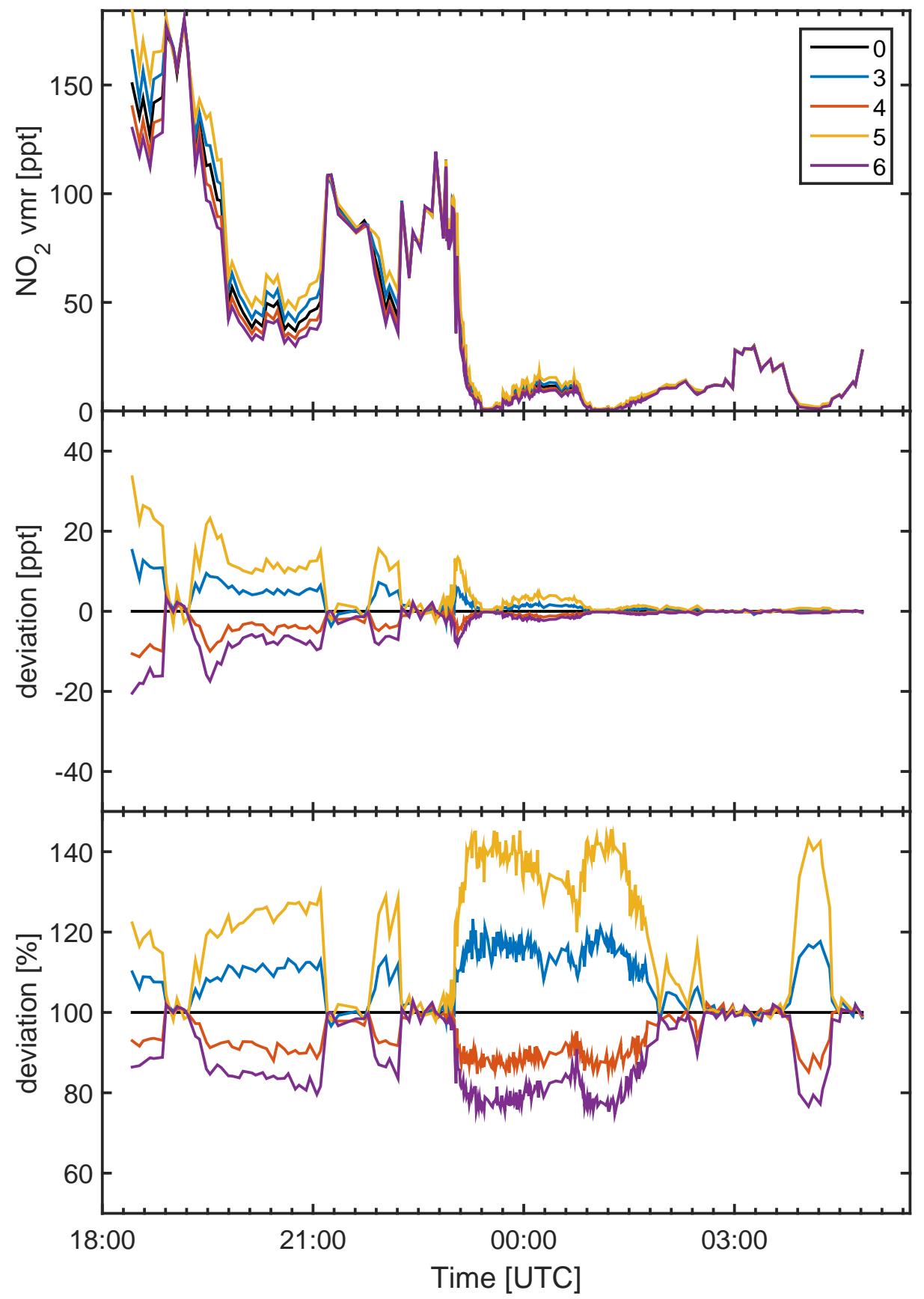

Figure S3. Sensitivity runs 0 (base run), 3, 4, 5, and 6 for $\mathrm{NO}_{2}$, according to the parameters given in Table 5 . 


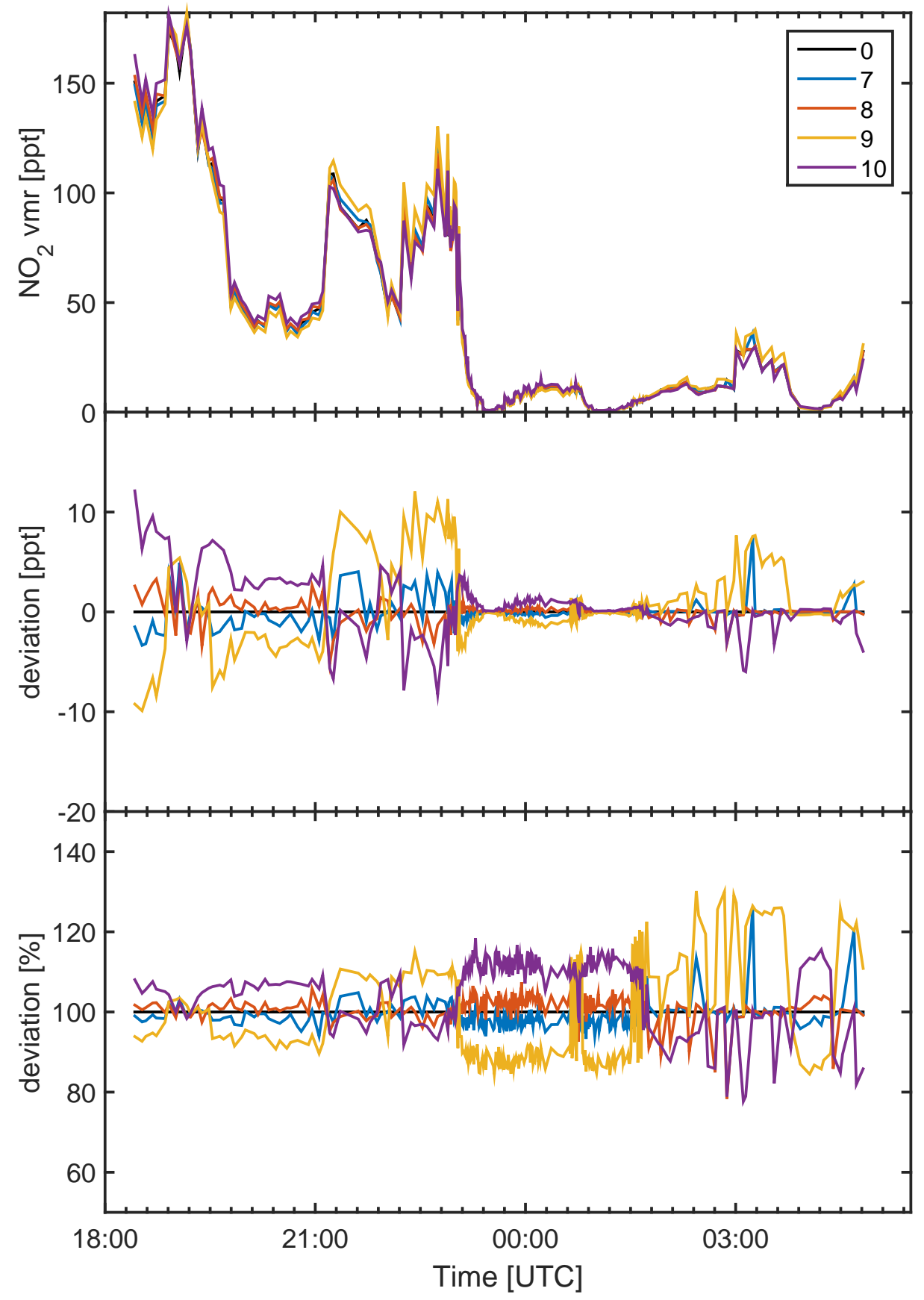

Figure S4. Sensitivity runs 0 (base run), 7, 8, 9, and 10 for $\mathrm{NO}_{2}$, according to the parameters given in Table 5. 


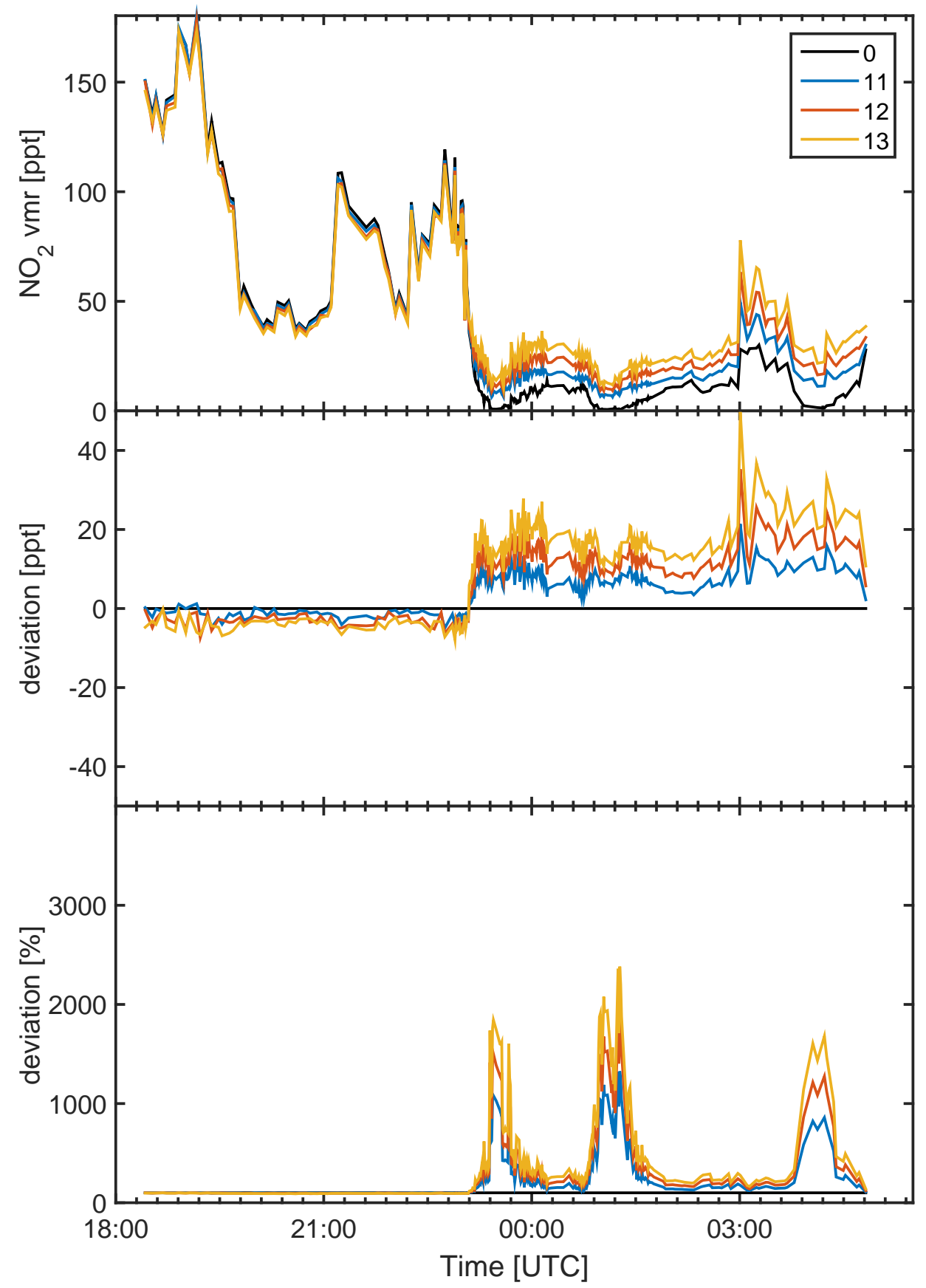

Figure S5. Sensitivity runs 0 (base run), 11, 12, and 13 for $\mathrm{NO}_{2}$, according to the parameters given in Table 5 . 


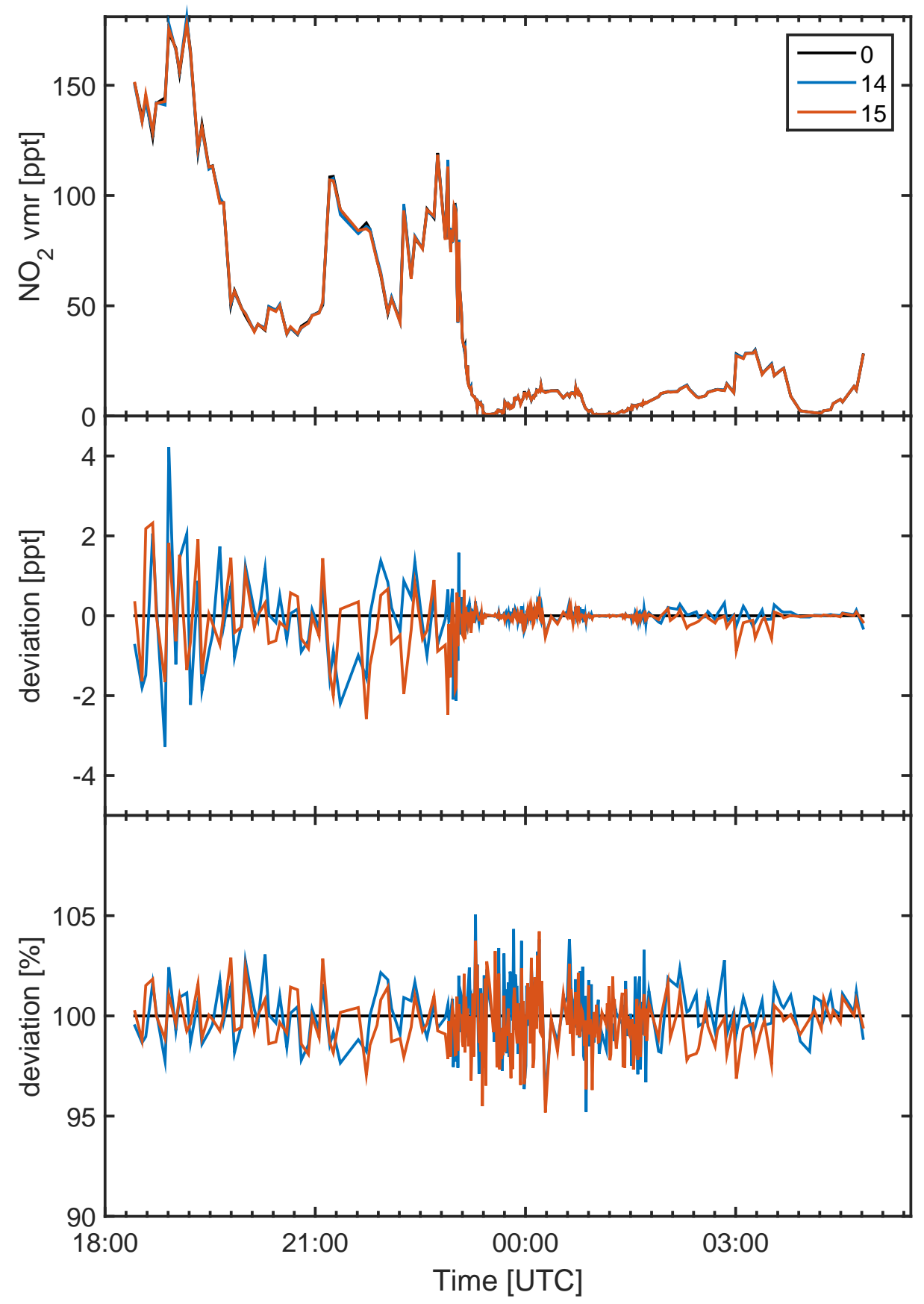

Figure S6. Sensitivity runs 0 (base run), 14, and 15 for $\mathrm{NO}_{2}$, according to the parameters given in Table 5 . 


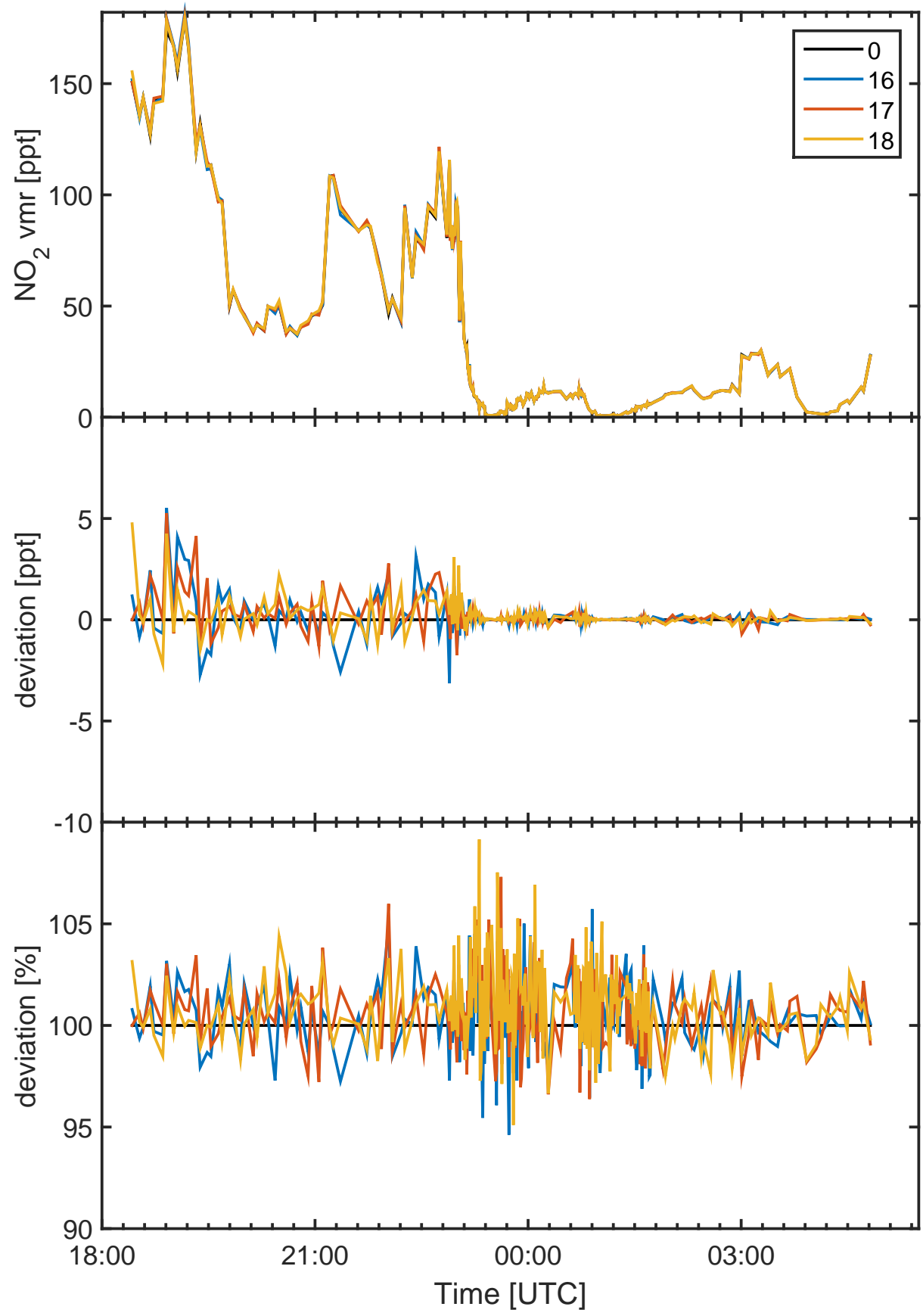

Figure S7. Sensitivity runs 0 (base run), 16, 17, and 18 for $\mathrm{NO}_{2}$, according to the parameters given in Table 5 . 


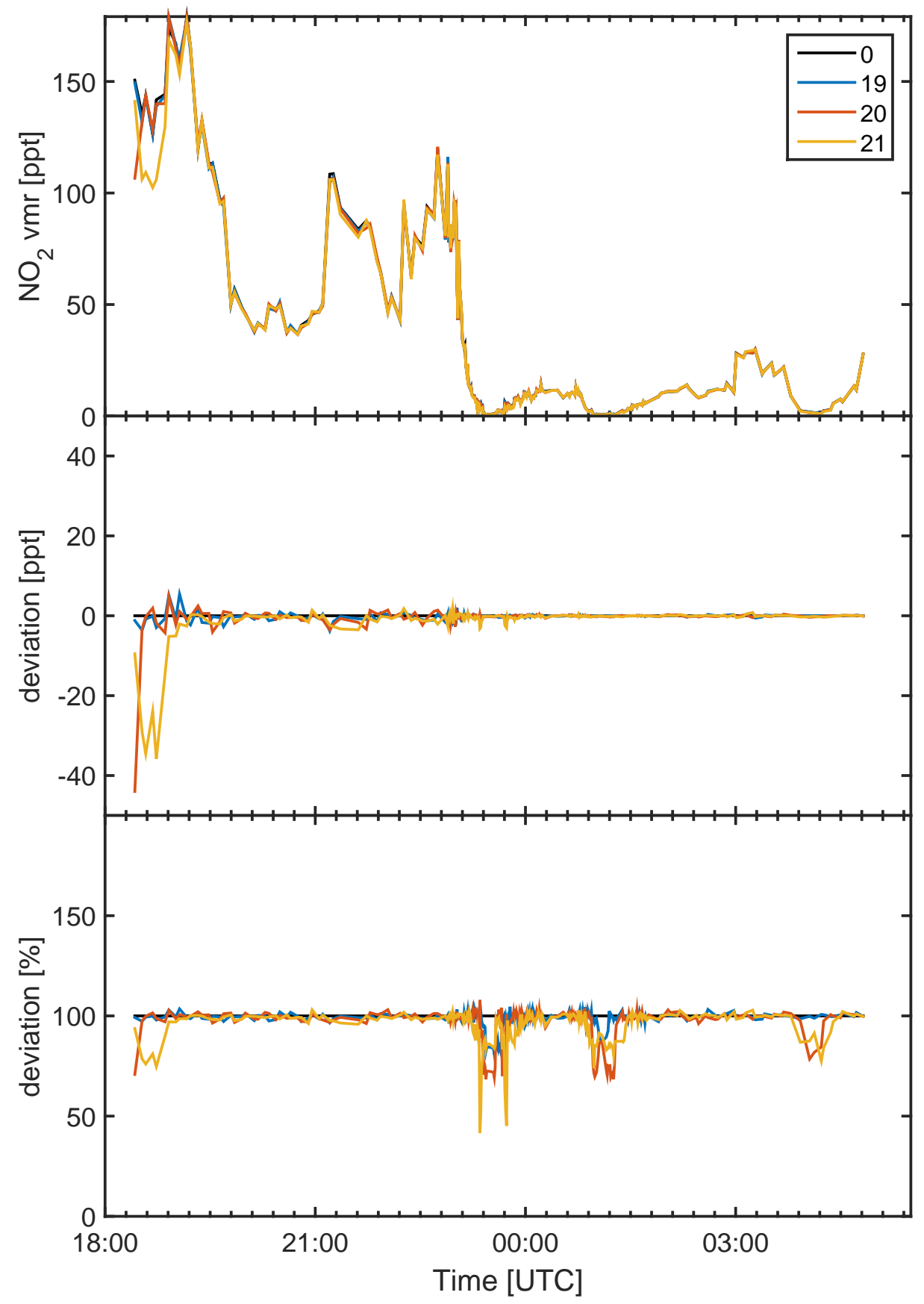

Figure S8. Sensitivity runs 0 (base run), 19, 20, and 21 for $\mathrm{NO}_{2}$, according to the parameters given in Table 5 . 


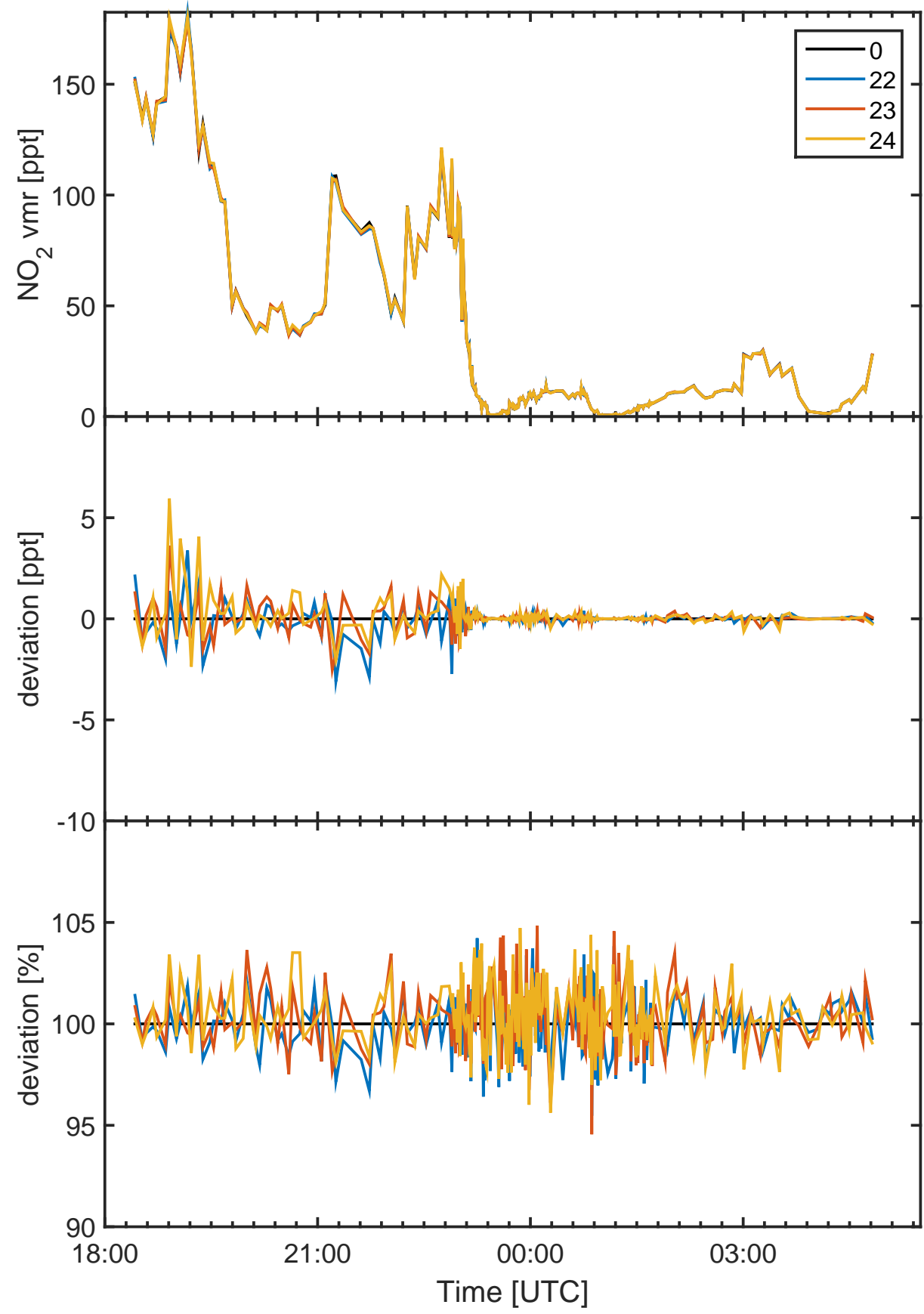

Figure S9. Sensitivity runs 0 (base run), 22, 23, and 24 for $\mathrm{NO}_{2}$, according to the parameters given in Table 5 . 


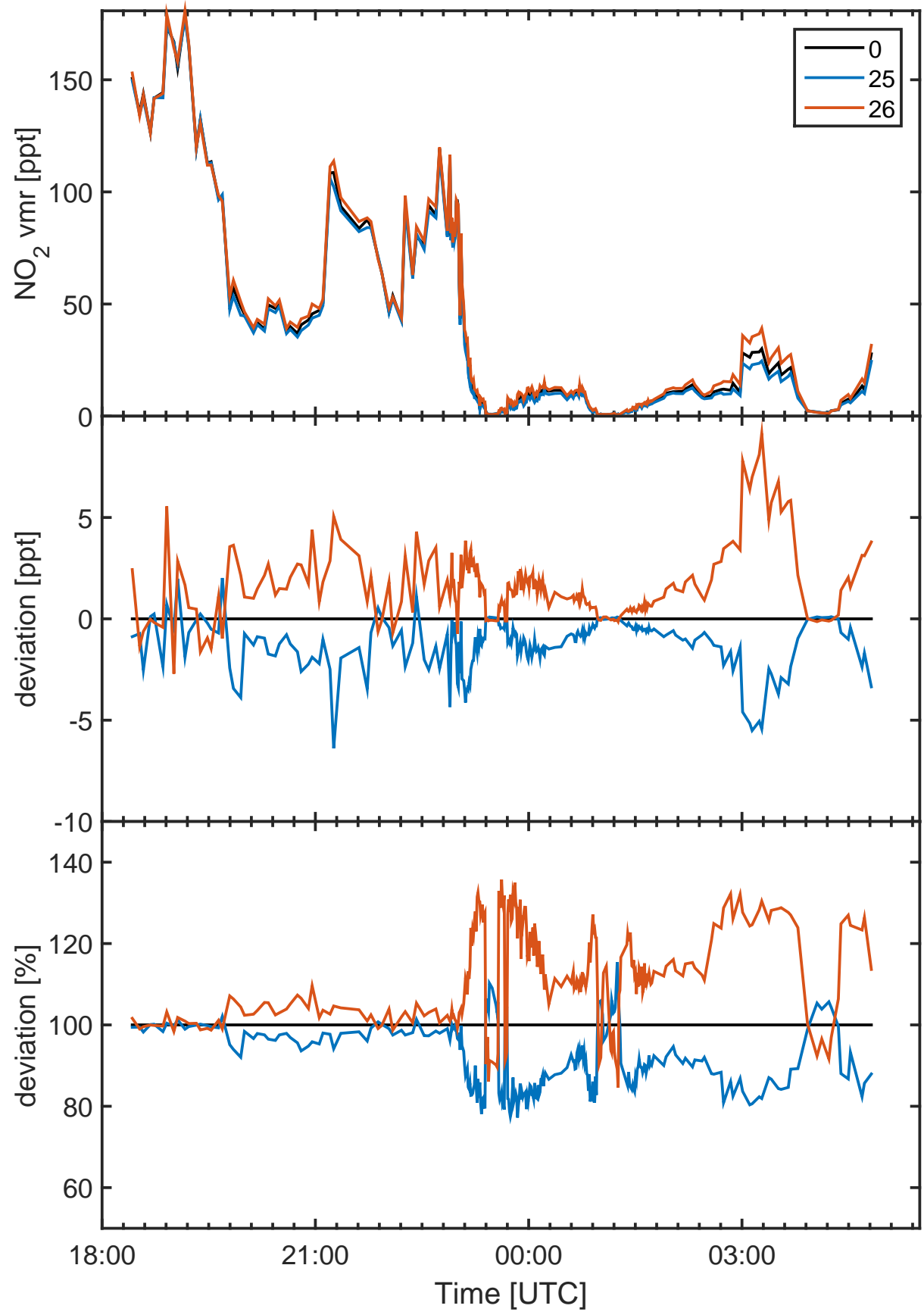

Figure S10. Sensitivity runs 0 (base run), 25, and 26 for $\mathrm{NO}_{2}$, according to the parameters given in Table 5 . 


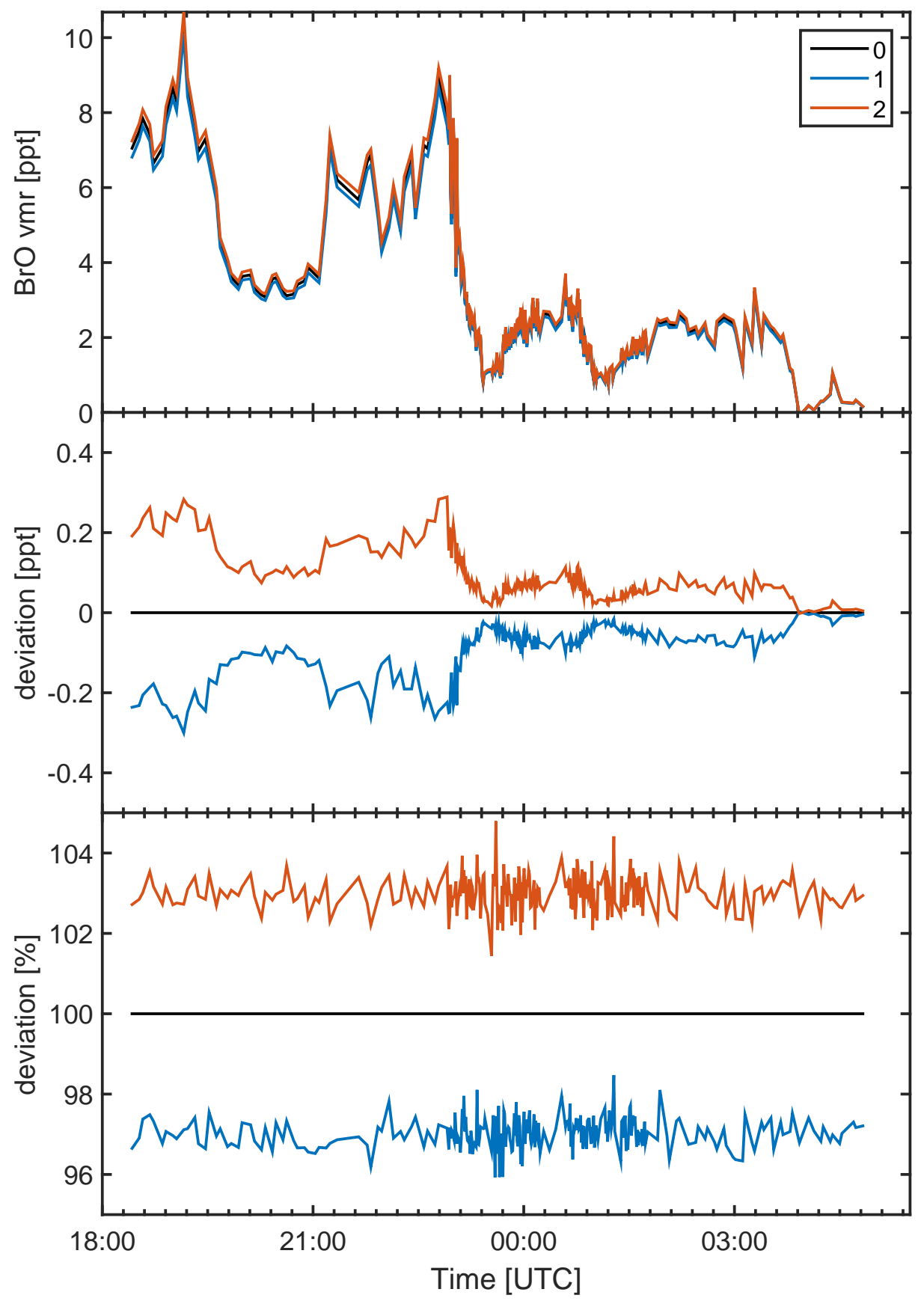

Figure S11. Sensitivity runs 0 (base run), 1, and 2 for $\mathrm{BrO}$, according to the parameters given in Table 5. 


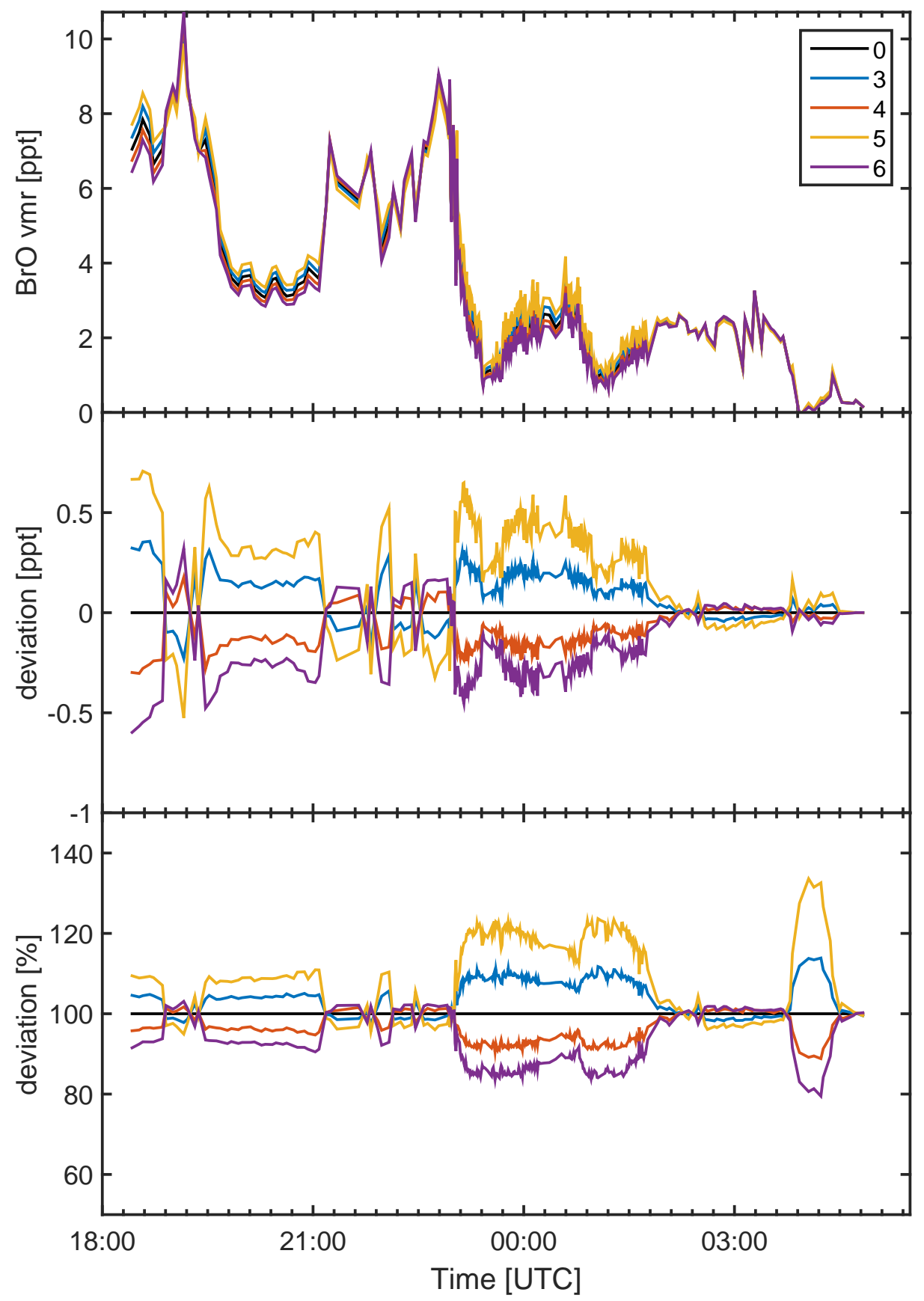

Figure S12. Sensitivity runs 0 (base run), 3, 4, 5, and 6 for $\mathrm{BrO}$, according to the parameters given in Table 5. 


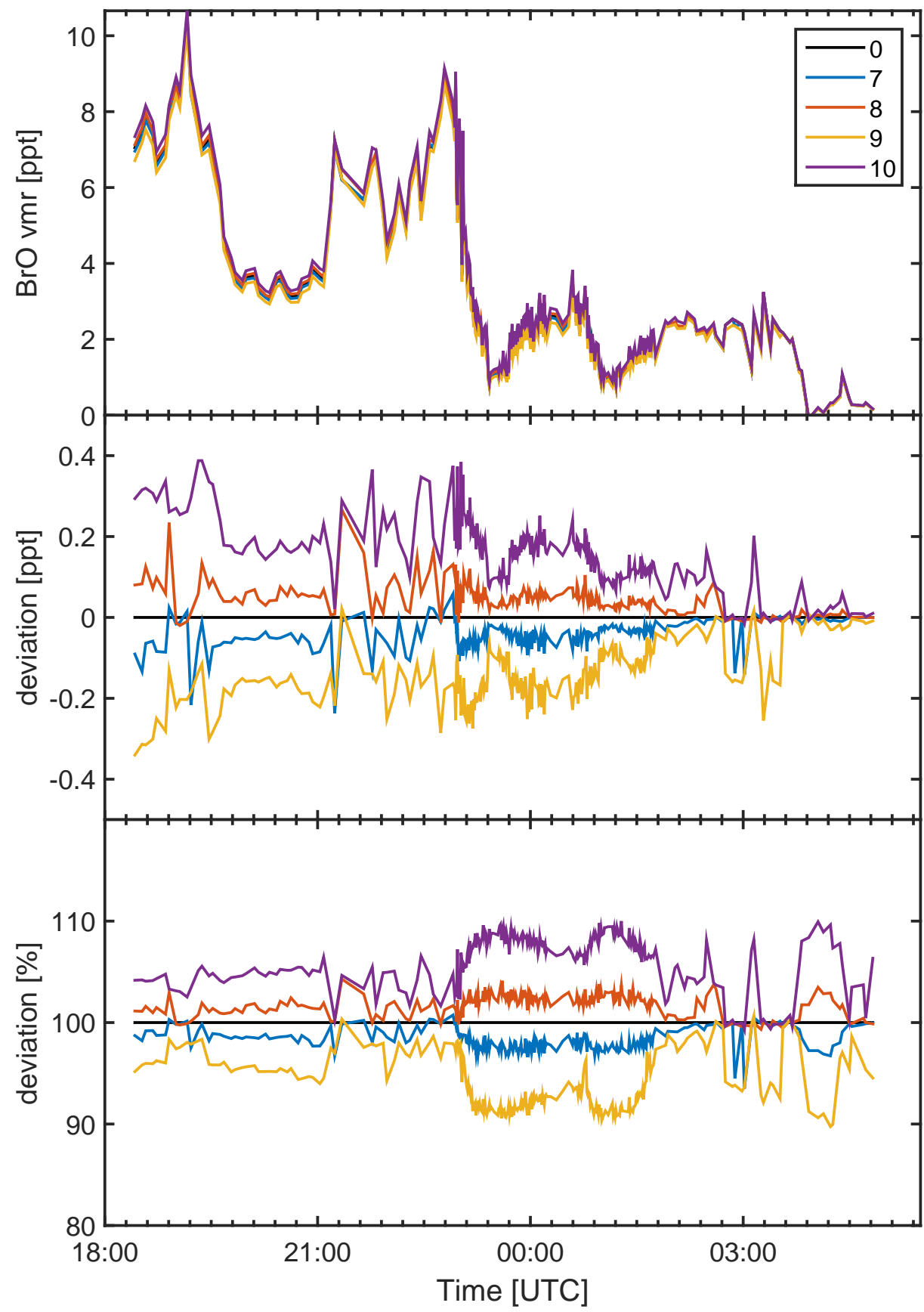

Figure S13. Sensitivity runs 0 (base run), 7, 8, 9, and 10 for $\mathrm{BrO}$, according to the parameters given in Table 5. 


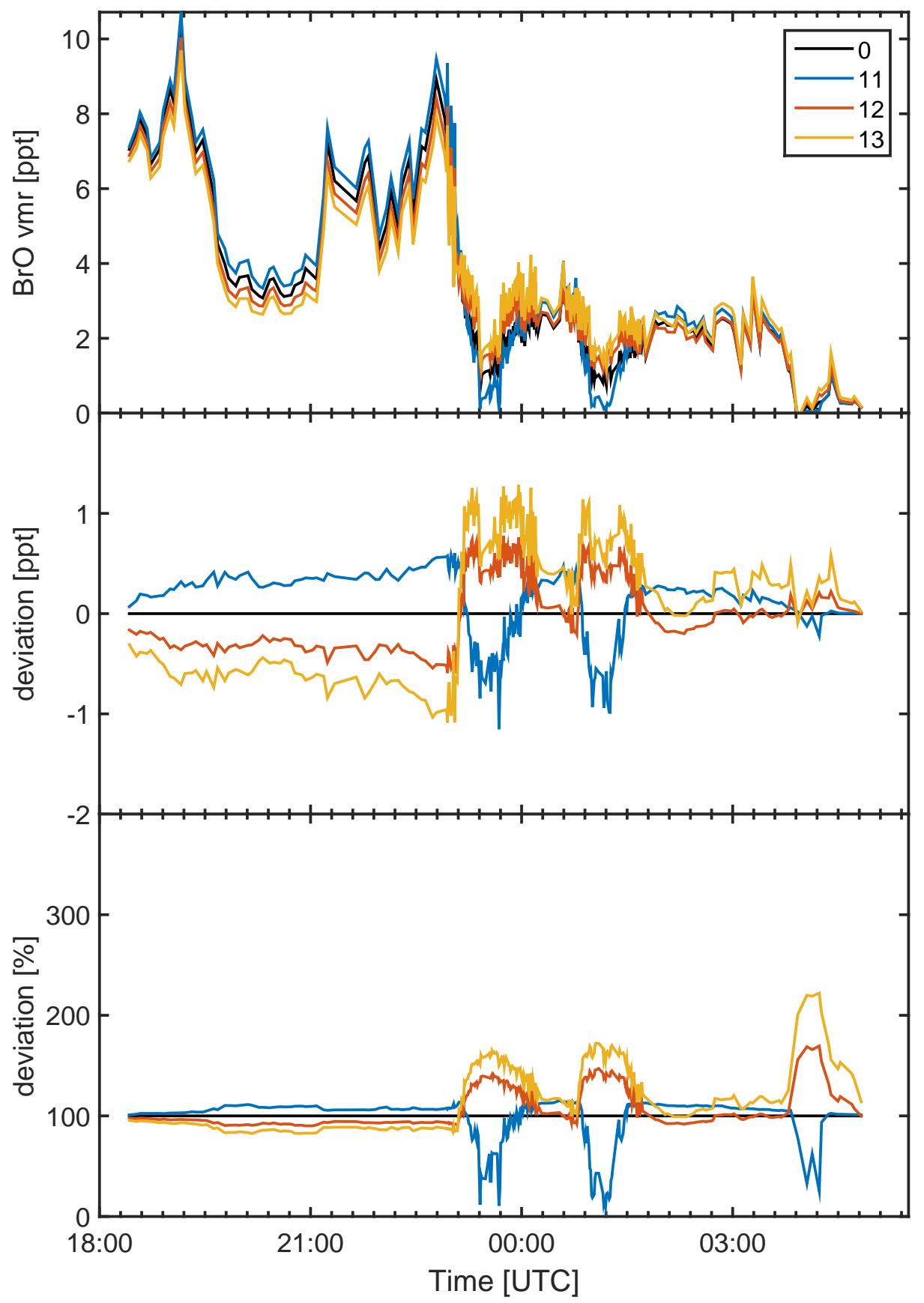

Figure S14. Sensitivity runs 0 (base run), 11, 12, and 13 for $\mathrm{BrO}$, according to the parameters given in Table 5. 


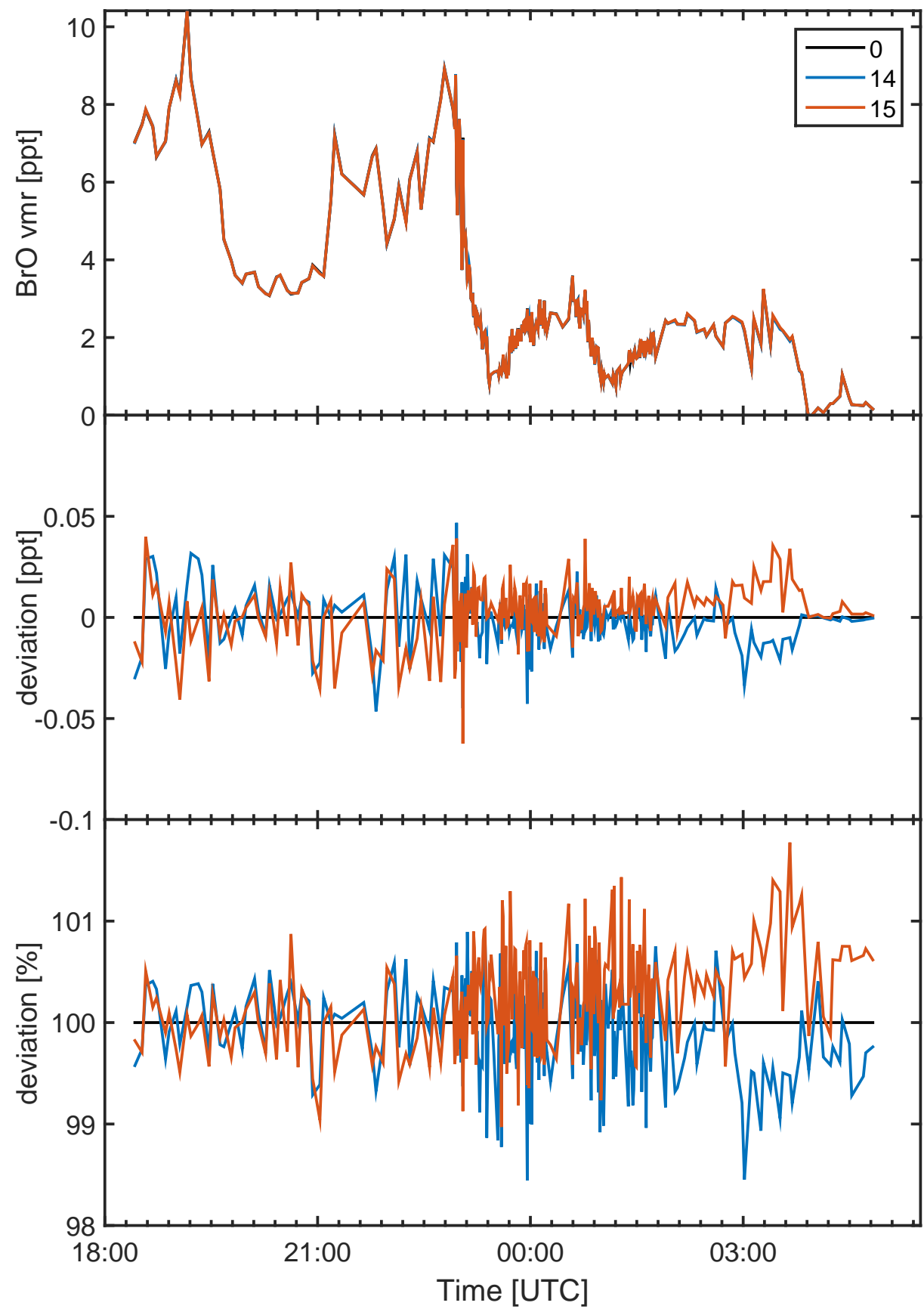

Figure S15. Sensitivity runs 0 (base run), 14, and 15 for $\mathrm{BrO}$, according to the parameters given in Table 5. 


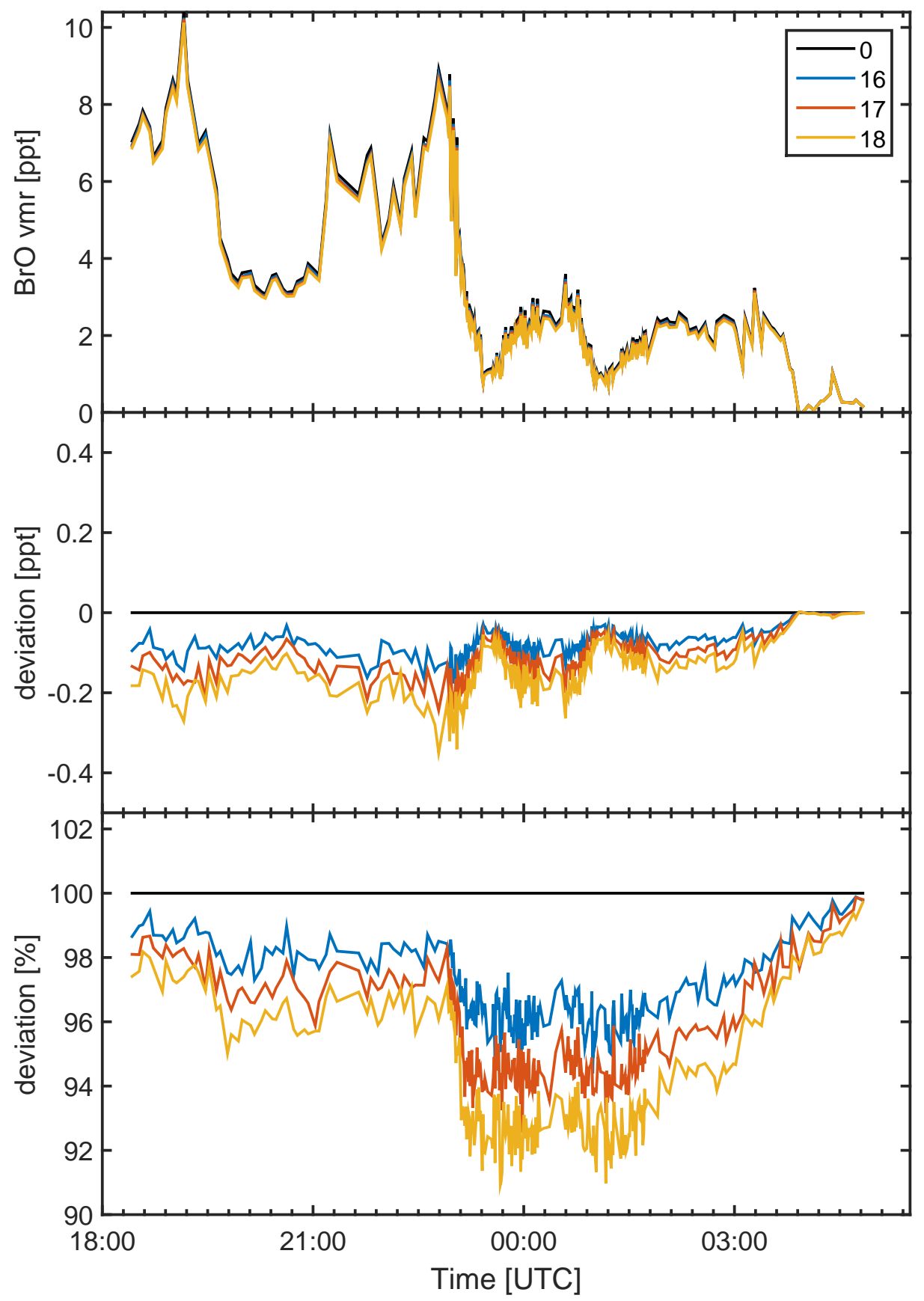

Figure S16. Sensitivity runs 0 (base run), 16, 17, and 18 for $\mathrm{BrO}$, according to the parameters given in Table 5. 


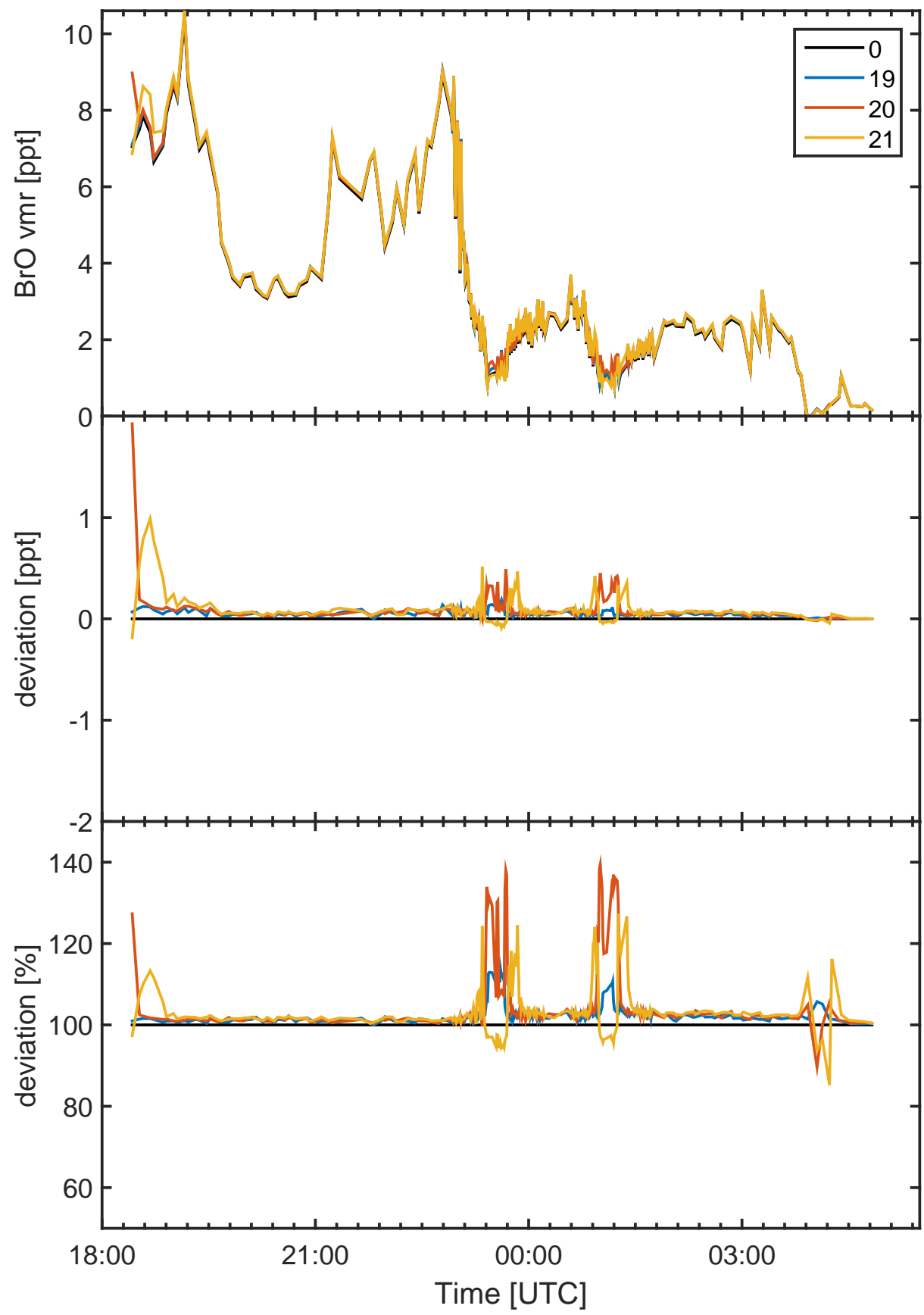

Figure S17. Sensitivity runs 0 (base run), 19, 20, and 21 for $\mathrm{BrO}$, according to the parameters given in Table 5. 


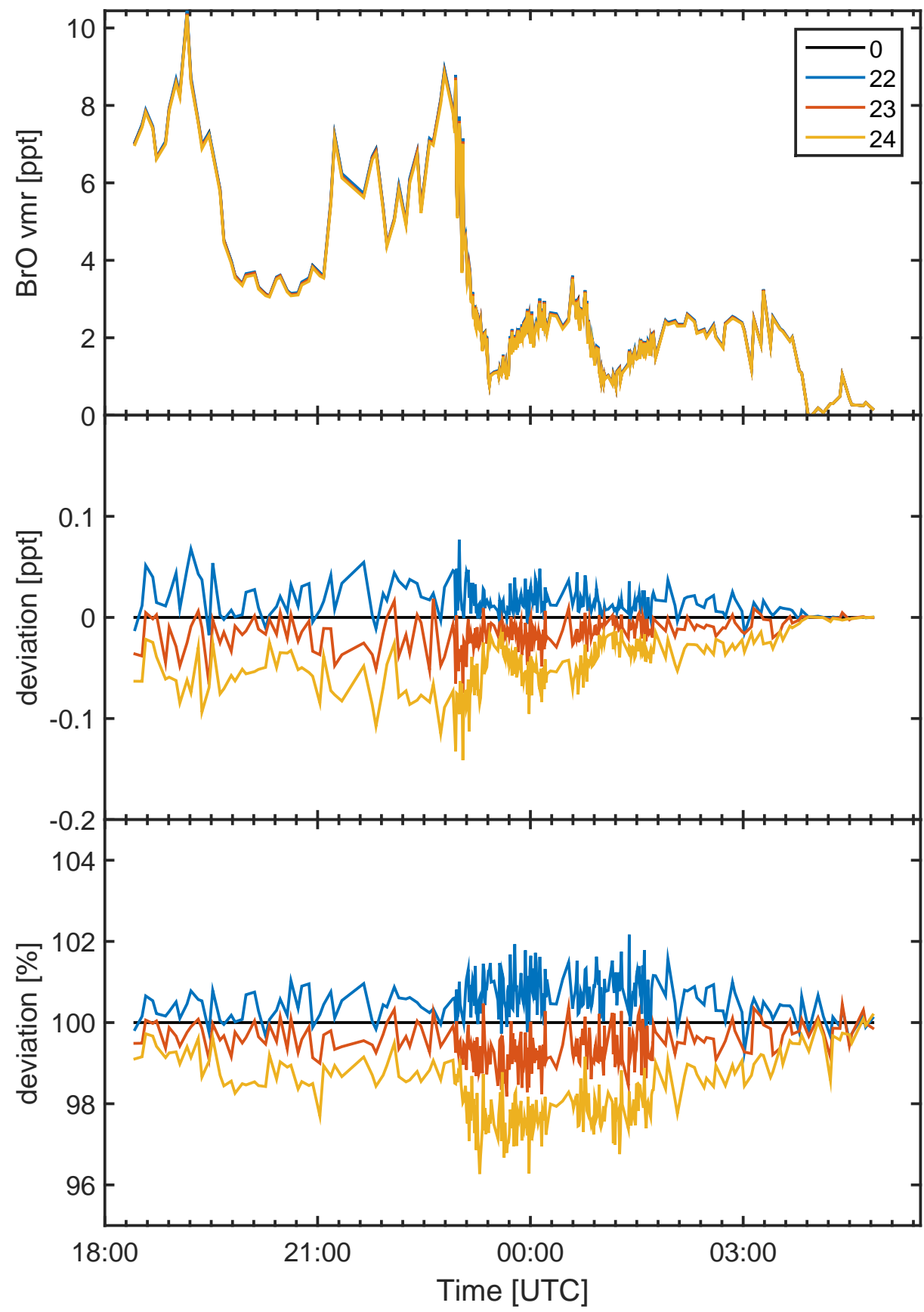

Figure S18. Sensitivity runs 0 (base run), 22, 23, and 24 for $\mathrm{BrO}$, according to the parameters given in Table 5. 


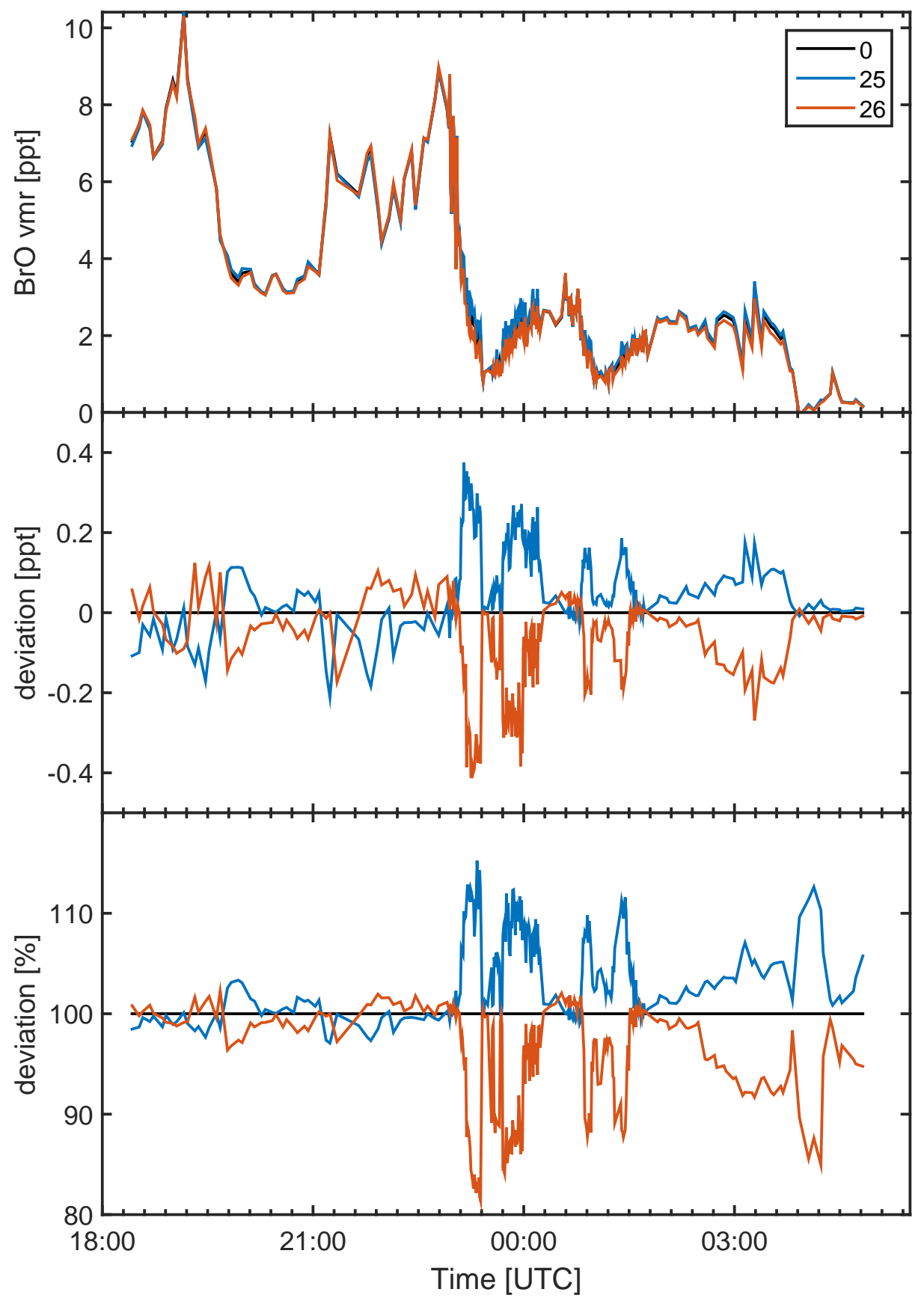

Figure S19. Sensitivity runs 0 (base run), 25, and 26 for $\mathrm{BrO}$, according to the parameters given in Table 5. 